\title{
How Religious Faith Affects Beliefs on Poverty: A Study in Italy
}

\author{
M. Norcia and A. Rissotto
}

\begin{abstract}
This study analyses the attributions of causality and the representations about poverty in order to better understand people's perception and to suggest adequate and shared interventions. The data we analyzed refer to a 2012 research which has been carried out on a sample of 1000 participants in Italy. Preliminary analysis has been conducted in order to get the relation among attribution of causality for impoverishment and religious beliefs to emerge. Further multivariate analysis has tested the relation net of other dimension as economic status (income), sex and education level.
\end{abstract}

Index Terms-Poverty, causal attribution for poverty, religion and poverty.

\section{INTRODUCTION}

"All of us are continuously faced with the problem of deciding whether what happens to us is contingent on our own behavior and can be controlled by our own actions or whether it depends upon luck, the intervention of powerful others, or influences which we cannot understand"'[1].

In this sentence, Rotter explains the mechanism of causal attribution: during life period, indeed, people try to understand the origin of whatever is or happens around them, to find the correct strategies to deal with it.

In this paper the causal attributions for poverty will be deepened, that is how people perceive factors that could drive to such conditions: why do people become poor? Do people believe that poverty results from insufficient individual effort or - for instance - from failures of the economic system?

Answers to these question have a lot of important implications on people's behavior: as Furnham says clearly, "attributions are related to behavior: whether one votes, and for whom; which newspapers are read and which television channels are watched; the extent of personal charitable donations and which charities are chosen to receive these; the disposition to do voluntary work of any kind; even where one chooses to take a vacation." [2].

Focusing on psychological concepts such as causal attribution reflects a different approach in studying poverty from traditional ones, which are mainly based on income or consumption. This different approach considers poverty as a multidimensional concept that implies a substantial lack at the economic level as well as at social and psychological levels. Poverty should be considered in a multidimensional way, because it not only means earning low wages, but it

Manuscript received December 20, 2012; revised February 20, 2013.

M. Norcia and A. Rissotto are with the Institute of Cognitive Sciences and Technologies - National Research Council (e-mail: maurizio.norcia@istc.cnr.it, antonella.rissotto@istc.cnr.it). often includes being less educated, adapting personal aims and aspirations to limited resources, and not being able to rely on a family or on a group of friends.

Furthermore, "stratification is a basic aspect of society" [3] and this is the reason why topic about attributions for social stratification has generated since " $60 \mathrm{~s}$ what Wilson defines a "growing amount" [4] of research studies in sociopsychological and economic field.

A review of the literature allows us to reconstruct the landscape of theories of social stratification from both the social perception (people's attributions) and the examination of welfare programs: as Bradshaw describes [4, p.8], indeed, "community anti-poverty programs are designed, selected, and implemented in response to different theories about the causes of poverty that 'justify' the community development interventions", or "different views about the underlying causes of poverty lead to very different policy choices" [5].

From literature, three main streams emerge in which placing the different theories about phenomenon of poverty: a first group comprises the attributions that seek for responsibility of individual's condition in his own effort and abilities and in his "own doing or not doing" [6]-[8]. "Just world theory", for instance, upholds the idea that people have "what they merit" that is what 'mathematically" derives from their actions [6]: that's what Feagin [9] calls "Social darwinism". A second group, in contrast, comprises contextual factors and trace poverty/wealth status back to structural variables: Bradshaw [4] talks explicitly about "culture of poverty" as a subculture of poor people in which they develop a set of shared values and norms that is separate from the culture of the main society. Likewise the Dominant ideology thesis [10] underlines the importance of cultural factors: in all societies, the subordinate classes "introject" the socio-cultural values of the predominant class. According to "Public arena theory", several social phenomena - like poverty - are built in specific 'places', the so-called 'public arenas' (media, cinema, science, etc.). In these places, social problems "are discussed, selected, defined, framed, dramatized, packaged, and presented to the public." [11]. Gwartney\&McCaleb [12], finally, talk about "Welfare dependency", that is the creation of disincentives to work caused (and consequently poverty) by cash assistance programs [5], [6], [13]. The third set, finally, emphasizes "no tangible" explanations and includes attributions referred to God's will, fate or bad luck [14], [15].

Several studies, however, demonstrates that people often have more than one sole belief about poverty: people, indeed, consider poverty as the result of the interaction between several factors, among which they detect sometimes a prevalent one. This kind of attributional behavior reflects what upheld by the "Cyclical Theory", that 
considers poverty as originating from a sort of 'spiral' of problems of different kind can create disinvestment and decline at community level and individual level (people become poorer and consequently less self-confident and so forth) [4].

\section{What INFLUENCES BELIEFS ABOUT POVERTY?}

Poverty and deprivation are multidimensional phenomena that encompass various facets of people's life: economic dimension, such as (lack of) income or assets; but also psychological and social aspects. In the last decades an increasing, huge number of studies have emphasized how, for instance, a poor social capital, or scarce sense of control may be part of a deprived condition. The same richness of pieces making up the jigsaw of poverty emerges if considering the dimensions influencing people's beliefs about poverty. Several studies, indeed, bring out a relation among cultural, social, economic and demographic characteristics of individuals and attributions they make for poor people and for poverty. For instance, many studies, examined the effects of real or perceived socioeconomic status, age, sex, education, political ideology, religious beliefs [4], [17], [18], [19].

Literature on relation between religion and beliefs about poverty is quite poor [19]: research seems to have neglected - curious! - to study the effects of theodicy, that is the way religion explains the functioning of social life and distribution of rewards and chances [20].

The early studies that focus on religion and attribution for social inequalities take into account different religions (Catholics, Protestants, Jews but also atheists) in different contexts - United States and Australia - and cross faith with other socioeconomic dimension like race and age [21], [22].

From these researches it emerges that Catholics and Protestants choose individualistic attributions more frequently than other respondents. Furthermore, Catholics and Jews seem to prefer fatalistic causes. The race seems to be an important factor in shaping attributions for poverty: black protestants, for instance, turn out to be less individualist and more structuralist than white ones. It seems to support a sort of "religious underdog" perspective, whereby members of "minority" religions tend to support "system-challenging" ideas, against pro status-quo beliefs.

Kluegel and Smith [22], in their rigorous research in the United States, show that atheists are less individualistic than religious people; in the scale of individualistic beliefs, on the contrary, Catholics and Protestants are ranked in the highest positions. In this case, as well, it also emerges that religious people tendentially choose to be thankful to God for personality traits or individual abilities [23], "since they may be viewed as gifts from God" (ivi:1138).

Hunt [19] completed almost 3000 interviews in California. From his research it has emerged that Catholics and Protestants choose individualistic explanation of poverty more frequently than others. Protestants seem to be less structuralist than Catholics and Jews, but more than nonreligious people. Protestants result less fatalistic than Catholics (the most fatalistic in the sample), Jews and even less than non-religious people. Furthermore outcomes of Hunt's research seem to support "religious underdog" thesis:
Protestants and Catholics (the "dominant" religions in that context) more frequently support the traditional ideological interpretation of poverty that is individualistic. Members of religious minorities are more likely to endorse the systemchallenging, structuralist view of poverty.

This article will focus on religion and on the relation between religious beliefs and opinions about ways people become poor. In view of a scarce international literature on this topic, studies regarding Italy are almost absent and it appears really curious given the remarkable importance of religion in this Country, home, moreover, of the Roman Catholic Church. Catholic is most widespread religion in Italy: in 2006 almost $90 \%$ of population declares itself as Catholic [24], whereas from recent studies [25] it emerges that almost $50 \%$ of Italian people defines as "granitic" his faith in God; $25,1 \%$ declares itself "faithful, though having some doubts about it", whereas $11,8 \%$ talks about a "fluctuating" faith, that is admits presence of God in some periods of its life and does not admit it in other periods.

Studying relation between religious faith and attribution for poverty reflects the very nature of poverty: a complex, multidimensional, multifaceted and, above all, contextual phenomenon. Vision about poverty, and consequently connected policies, is strictly tied with the context we consider. This is the reason why we can't talk about everywhere (and always) valid visions and, hence, is important studying specific context like the Italian one.

\section{METHOD}

The data used in this investigation were gathered between January and March 2012 in the region of Lazio. Research has been carried out on almost 1000 subjects: it has allowed us to handle a large sample, wide-ranging at a sociodemographic level.

The sample has been stratified by three sociodemographic variables: population size of municipality of residence, sex, and age. The strata sample was calculated by census data gathered from the National Institute of Statistics (ISTAT) about resident population in Lazio on January 1, 2008.

In the table below (Table I), main demographic data are shown.

\begin{tabular}{|c|c|c|c|c|c|c|c|c|c|c|c|}
\hline & \multicolumn{3}{|c|}{ Education $^{1}$} & \multicolumn{3}{|c|}{ Age (years) } & \multicolumn{3}{|c|}{ Sex } & \multicolumn{2}{|r|}{ Total } \\
\hline & 5 & 3 & $\underset{\stackrel{\mathbb{q}}{\sim}}{\stackrel{I}{\sigma}}$ & $\begin{array}{l}\stackrel{0}{1} \\
\stackrel{1}{\perp}\end{array}$ & 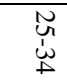 & $\begin{array}{l}\vec{u} \\
\stackrel{+}{+}\end{array}$ & $\begin{array}{l}\stackrel{\leftrightarrow}{u} \\
\dot{u} \\
\stackrel{A}{A}\end{array}$ & $\begin{array}{l}u \\
\text { un } \\
\grave{\alpha}\end{array}$ & $\begin{array}{l}\text { जे } \\
+\end{array}$ & 3 & $T$ \\
\hline $\mathrm{N}$ & 390 & 421 & 181 & 108 & 172 & 190 & 154 & 143 & 225 & 478 & $514 \quad 992$ \\
\hline$\%$ & 39,3 & 42,4 & 18,2 & 10,9 & 17,3 & 19,1 & 15,5 & 14,4 & 22,7 & 48,1 & $\begin{array}{ll}51,9 & 100\end{array}$ \\
\hline
\end{tabular}

This study considers data for a sub-sample of respondents: indeed, in our analyses we have compared people declaring themselves as Catholic to people declaring themselves as non-religious (atheists); furthermore, amongst Catholics, we have considered just respondents who reported a medium strong faith or "religious behaviours" (behave in accordance

${ }^{1}$ Education levels: Low (primary and middle school); Mid (high school); High (degree and post-degree). 
to religious values, taking part to religious practices steadily, ...), with the aim of better highlight differences between groups: in Italy a sizable quantity of person is baptized as Christian by tradition, but do not talk about them as believers or practicing.

The following table (Table II) shows a set of demographic characteristics of this subsample.

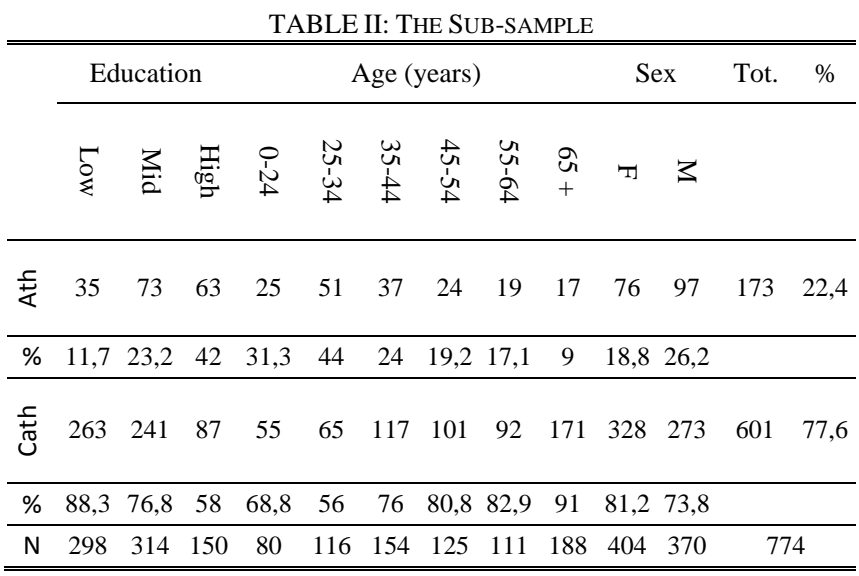

\section{Poverty Perceived Causes}

To detect poverty perceived causes, the following introductive question has been addressed to all respondents: "In your opinion, which events could lead people to poverty?" The suggested poverty attributions have been: lack of ability; bad luck; lack of effort; loose morals; discrimination; lack of equal opportunities; failure of the economic system. The following step has been to ask respondents to indicate their concordance rate per item, according to a 5-point Likert scale. The outcomes of the PCA have allowed to explain an adequate amount of variance (more than 62\%) and to detect three main factors for poverty: the first factor can be interpreted as internal attribution, and the other detected component is related to external attribution. The PCAs have furthermore allowed to detect a distinction into the external component: it emerges, namely, a first component that we could name "Powerful Others" and a second component, "Fatalistic". The names we have used have been borrowed by Levenson [26] and indicate, on the one hand, elements external to the individual (other people, government, labor market...); on the other hand, supra-individual but nonstructural explanations (God, Providence, but also Destiny, Luck/Bad luck...). The PCA's factor loadings let us draw one important conclusion: data show that there is no significant inverse relationship between different causal attributions: individuals, who tend, for instance, to choose internal attributions, do not necessarily choose less external explanations.

\section{FAITH AND PRACTICE}

Faith (or non-faith) and level of practicing have been detected by using two separate questions. Both questions were introduced by the sentence: "If you are a believer, how do you consider yourself?" Then, two five-step scales ("notbeliever/strongly believer", "not practicing/practicing") have been shown to the subject. In this contribution, as stated earlier, we are considering among Catholics just those reporting medium-high levels (steps 3-5) of faith/practice. Analysis show similar trends as the 2008 European Value Study [27] for low and medium levels of faith (see Table III). On the contrary, strong faith people seem to be more numerous in our study.

TABLE III: COMPARISON WITH 2008 EUROPEAN VALUE STUDY

\begin{tabular}{|c|c|c|}
\hline Levels $^{2}$ & 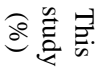 & 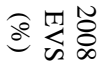 \\
\hline "not believer" / "not at all important" & 3,7 & 2,5 \\
\hline "low faith"/ "not important" & 6,1 & 10,5 \\
\hline "medium faith" / "quite interested" & 39,4 & 47,7 \\
\hline $\begin{array}{l}\text { "strong faith", "really strong faith" / "very } \\
\text { interested" }\end{array}$ & 50,8 & 39,3 \\
\hline
\end{tabular}

\section{RESULTS AND DisCUSSION}

TABLE IV: CAUSAL ATTRIBUTION FOR POVERTY IN MEDIUM-STRONG FAITH CATHOLICS AND ATHEISTS

\begin{tabular}{|c|c|c|c|c|c|c|c|}
\hline Attrib & $\begin{array}{l}\text { pondents } \\
\text { ns }\end{array}$ & Ath. & Cath. & Tot. & $X^{2}$ & $\mathrm{df}$ & $p$ \\
\hline$\overline{E-P^{3}}$ & $\Delta^{4}$ & 9,5 & $-9,5$ & 418 & 13,749 & 2 & ,001 \\
\hline$\overline{E-F}$ & $\Delta$ & $-17,2$ & 17,2 & 163 & & & \\
\hline $\mathrm{I}$ & $\Delta$ & 7,7 & $-7,7$ & 122 & & & \\
\hline Total & & 169 & 534 & 703 & & & \\
\hline
\end{tabular}

All charts included in this contribution show differences between observed and expected data.

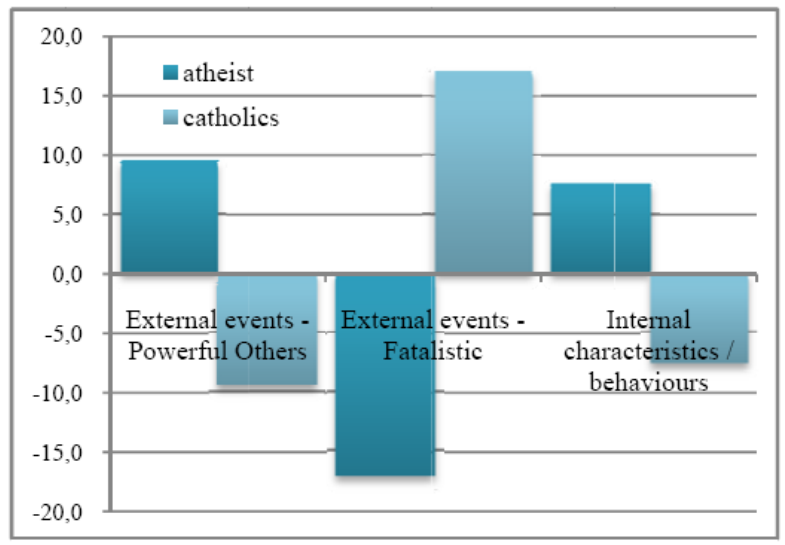

Fig. 1. Causal attribution for poverty in medium-strong faith Catholics and atheists

As crosstab shows (Table IV), strong believers Catholics seem to prefer fatalistic explanations of poverty (significantly) more than expected. On the contrary, atheists respondents choose - more than expected - both internal and external factors.

Table $\mathrm{V}$ examines differences in causal attributions between practicing Catholics and atheists: it shows a similar trend as Table IV that is atheists choose more than expected external and internal explanations of the phenomenon, in

\footnotetext{
${ }^{2}$ The sentences before the slash refer to this study. On the contrary, sentences after the slash refer to the 2008 EVS

${ }^{3}$ From now on, following acronyms will be used: "E-P": "External Powerful others"; "E-F": "External - Fatalistic"; "I": "Internal".

4 " $\Delta "=$ difference between observed frequency and expected (theoretical) frequency.
} 
comparison with Catholics.

Both these results highlight that Catholics tend to prefer explanations referring to a transcendent level; we can hypothesize God or Holy Providence.

TABLE V: CAUSAL ATTRIBUTION FOR POVERTY IN PRACTICING CATHOLICS AND ATHEISTS

\begin{tabular}{|c|c|c|c|c|c|c|c|}
\hline $\begin{array}{l}\text { Resp. } \\
\text { Attrib. }\end{array}$ & & $\stackrel{\gtrless}{F}$ & $\begin{array}{l}\stackrel{f}{F} \\
\stackrel{f}{F}\end{array}$ & $\stackrel{\vec{\rho}}{\stackrel{+}{\prime}}$ & $X^{2}$ & $\mathrm{df}$ & $p$ \\
\hline E-P & $\Delta$ & 10,8 & $-10,8$ & 307 & 12,66 & 2 & ,002 \\
\hline E-F & $\Delta$ & $-15,8$ & 15,8 & 117 & & & \\
\hline I & $\Delta$ & 5 & -5 & 99 & & & \\
\hline Total & & 169 & 354 & 523 & & & \\
\hline
\end{tabular}

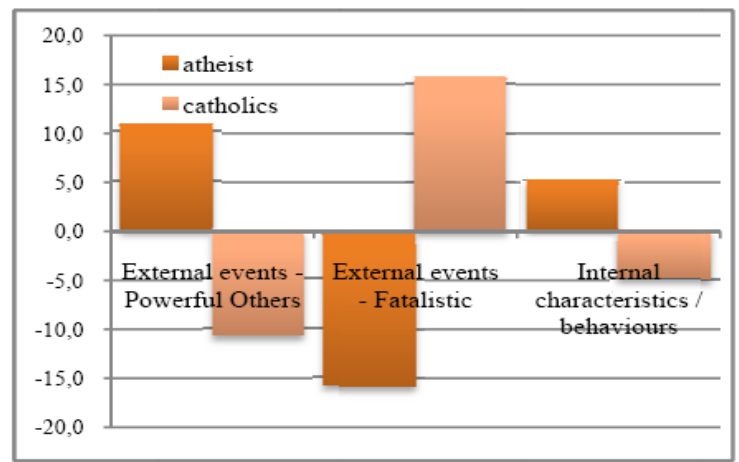

Fig. 2. Causal attribution for poverty in practicing Catholics and atheists.

Atheists, on the contrary, tend to reject this point of view: what happens to your life originate exclusively from actions you or other people do.

This attitude seems to endorse the underdog thesis [19], [28], that explains how out-group people (that is atheists: Italy is a traditionally Catholic Country) are more likely to support ideological challenges to the status quo: external (obviously not fatalistic) or internal explanations of poverty.

On the other hand, we can hypothesize that Catholics respondents reject internal factors for the same "sort of compassion", that takes the same individual to change his aptitude depending on whether he refers to wealth or to poverty [17].

Literature on this topic shows (apparently?) opposing outcomes: Hovemyr [29] in his research found that atheists endorse internal and external explanations of poverty, although not significantly.

TABLE VI: INCOME AS IV ${ }^{5}$ - STRONG FAITH RESPONDENTS

\begin{tabular}{|c|c|c|c|c|c|c|c|c|c|c|}
\hline \multicolumn{2}{|c|}{ Income } & \multicolumn{4}{|c|}{ Low } & \multicolumn{2}{|c|}{ Medium } & \multicolumn{3}{|c|}{ High } \\
\hline $\begin{array}{r}\text { Re } \\
\text { Attrib. }\end{array}$ & & $\stackrel{P}{F}$ & $\begin{array}{l}\hat{f} \\
\stackrel{f}{F}\end{array}$ & $\stackrel{\rightarrow}{\stackrel{\circ}{\circ}}$ & $\stackrel{\mathbb{F}}{F}$ & $\begin{array}{l}\Re \\
\tilde{F}\end{array}$ & $\stackrel{+}{\stackrel{P}{+}}$ & P & $\stackrel{\overbrace{}}{\rightleftarrows}$ & $\stackrel{-}{\stackrel{\circ}{\circ}}$ \\
\hline E-P & $\Delta$ & 9,9 & $-9,9$ & 88 & $-0,2$ & 0,2 & 177 & 0,6 & $-0,6$ & 36 \\
\hline$\underline{E-F}$ & $\Delta$ & $-6,9$ & 6,9 & 37 & $-6,7$ & 6,7 & 68 & $-0,8$ & 0,8 & 10 \\
\hline I & $\Delta$ & -3 & 3 & 21 & 6,9 & $-6,9$ & 60 & 0,3 & $-0,3$ & 16 \\
\hline \multirow{3}{*}{\multicolumn{2}{|c|}{ Total }} & 35 & 111 & 146 & 102 & 203 & 305 & 30 & 32 & 62 \\
\hline & & $\mathrm{X}^{2}$ & $\mathrm{df}$ & $p$ & $\mathrm{X}^{2}$ & $\mathrm{df}$ & $p$ & $\mathrm{X}^{2}$ & $\mathrm{df}$ & $p$ \\
\hline & & 15,5 & 2 &, 01 & 6,6 & 2 &, 04 &, 34 & 2 & 85 \\
\hline
\end{tabular}

On the contrary, Hunt's study [19] shows how Californian Catholics prefer individual and fatalistic factors.

\footnotetext{
${ }^{5}$ Intervening Variable
}

Since the proved, complex influence of socioeconomic factors on attributional level [30] we can hypothesize that this difference is originated from cultural elements that act as intervening variables on the relationship.

Several studies [21], [31], indeed, highlight the American - traditionally protestant - cultural attitude to focus more on the individual than on the context, also in the case of poverty: from the perspective of the self-made man, the poor gets the main responsible for his condition.

With the aim of analyzing the kind of influence these factors exert (as intervening variables) on the relation between religious faith/non-faith and causal attributions, further analyses have been made: sample has been divided in sub-groups according to the other variables taken into account (low/medium/high income, females/males, low/medium/high education) and frequencies have been observed.

\section{A. Income}

In case of income, sub-groups have been detected by using two thresholds: $60 \%$ and $200 \%$ of the median income of the total sample. These percentages are the same Eurostat uses to detect low income and wealthy people [31].

TABLE VII: INCOME AS IV - PRACTICING RESPONDENTS

\begin{tabular}{|c|c|c|c|c|c|c|c|c|c|c|}
\hline & \multirow{2}{*}{$\begin{array}{r}\text { Income } \\
\text { Resp. }\end{array}$} & \multicolumn{3}{|c|}{ Low } & \multicolumn{3}{|c|}{ Medium } & \multicolumn{3}{|c|}{ High } \\
\hline Attrib. & & $\stackrel{P}{*}$ & 尺ि & $\stackrel{\oplus}{\stackrel{\circ}{P}}$ & $\stackrel{\gtrless}{F}$ & $\stackrel{\vartheta}{\rightleftharpoons}$ & $\stackrel{+}{\circ}$ & $\underset{F}{\mathbb{P}}$ & $\stackrel{\Re}{\rightleftarrows}$ & $\stackrel{+}{\stackrel{\circ}{\circ}}$ \\
\hline E-P & $\Delta$ & 8,5 & $-8,5$ & 126 & 0,3 & $-0,3$ & 236 & 1,3 & $-1,3$ & 44 \\
\hline E-F. & $\Delta$ & $-5,3$ & 5,3 & 41 & $-10,9$ & 10,9 & 108 & 0,2 & $-0,2$ & 10 \\
\hline I & $\Delta$ & $-3,2$ & 3,2 & 29 & 10,6 & $-10,6$ & 66 & $-1,5$ & 1,5 & 25 \\
\hline Total & & 35 & 161 & 196 & 102 & 308 & 410 & 30 & 49 & 79 \\
\hline & & $\mathrm{X}^{2}$ & $\mathrm{df}$ & $p$ & $\mathrm{X}^{2}$ & $\mathrm{df}$ & $p$ & $\mathrm{X}^{2}$ & df & $p$ \\
\hline & & 10,99 & 2 & ,004 & 14,93 & 2 & ,001 & ,557 & 2 & ,757 \\
\hline
\end{tabular}

As it emerges from Table VII income seems not to influence relation among faith and causal attribution for poverty: trends are the same as before "grouping" for six crossings out of nine.

In group of wealthy people, difference between observed and expected frequencies is around zero: income seems to nullify the relation between the variables taken into exam in case of Fatalistic attributions (0,2 units).

Similarly, in case of internal attributions observed frequencies are alike to expected ones. In both cases, however, row marginal totals are the lowest in the table: this could explain why chi-squared is not significant

Similarly as seen with people with strong faith, income seems not to intervene significantly also in the case of practicing people: seven crossings out of nine are coherent with trends considering the whole sample (without grouping people with different incomes).

Being atheists or Catholics seems not to make difference in attributing poverty to internal factors among medium income people.

\section{B. Sex}

Dividing the sample according to sex, trends remain approximately the same as considering the whole sample. Trends differ in case of external - powerful others attributions (for females) and in case of internal attributions for males: sex seems to intervene more strongly on those 
attributions it traditionally shapes. In other cases it seems to be non influential.

TABLE VIII: SEX AS IV - STRONG FAITH RESPONDENTS

\begin{tabular}{|c|c|c|c|c|c|c|c|}
\hline & $\overline{\text { Sex }}$ & \multicolumn{3}{|c|}{ Females } & \multicolumn{3}{|c|}{ Males } \\
\hline Attrib. & Resp. & $\underset{F}{\rightleftarrows}$ & $\begin{array}{l}\stackrel{f}{F} \\
\stackrel{f}{*}\end{array}$ & $\stackrel{-1}{\stackrel{\rho}{\rho}}$ & $\underset{F}{2}$ & $\begin{array}{l}\Re \\
\stackrel{F}{F}\end{array}$ & 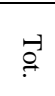 \\
\hline E-P & $\Delta$ & $-4,3$ & 4,3 & 185 & 15 & -15 & 233 \\
\hline$\overline{\mathrm{E}-\mathrm{F}}$ & $\Delta$ & $-3,2$ & 3,2 & 68 & $-13,2$ & 13,2 & 95 \\
\hline I & $\Delta$ & 7,5 & $-7,5$ & 83 & $-1,9$ & 1,9 & 39 \\
\hline Total & & 95 & 241 & 336 & 74 & 293 & 367 \\
\hline & & $\mathrm{X}^{2}$ & $\mathrm{df}$ & $p$ & $\mathrm{X}^{2}$ & $\mathrm{df}$ & $p$ \\
\hline & & 4,620 & 2 & ,099 & 17,844 & 2 & ,000 \\
\hline
\end{tabular}

TABLE IX: SEX AS IV - PRACTICING RESPONDENTS

\begin{tabular}{|c|c|c|c|c|c|c|c|}
\hline & Sex & & Females & & & Males & \\
\hline Attrib. & Resp. & $\underset{F}{\rightleftarrows}$ & 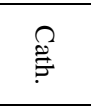 & $\stackrel{\oplus}{\stackrel{+}{\circ}}$ & $\underset{F}{P}$ & $\stackrel{\Re}{\tilde{F}}$ & $\stackrel{+}{\stackrel{\rho}{\circ}}$ \\
\hline$\overline{\text { E-P }}$ & $\Delta$ & 12,2 & $-12,2$ & 185 & 1,1 & $-1,1$ & 120 \\
\hline$\overline{E-F}$ & $\Delta$ & $-9,3$ & 9,3 & 57 & $-5,9$ & 5,9 & 56 \\
\hline I & $\Delta$ & $-2,9$ & 2,9 & 33 & 4,8 & $-4,8$ & 62 \\
\hline \multirow[t]{3}{*}{ Total } & & 74 & 201 & 275 & 93 & 145 & 238 \\
\hline & & $\mathrm{X}^{2}$ & $\mathrm{df}$ & $p$ & $\mathrm{X}^{2}$ & $\mathrm{df}$ & $p$ \\
\hline & & 4,18 & 2 & , 124 & 13,2 & 2 & ,001 \\
\hline
\end{tabular}

\section{Education}

TABLE X: EDUCATION AS IV - STRONG FAITH RESPONDENTS

\begin{tabular}{|c|c|c|c|c|c|c|c|c|c|c|}
\hline \multicolumn{2}{|c|}{ Education } & \multicolumn{3}{|c|}{ Low } & \multicolumn{3}{|c|}{ Medium } & \multicolumn{3}{|c|}{ High } \\
\hline Attrib. & Resp. & $\underset{F}{\stackrel{D}{F}}$ & . & $\stackrel{+}{\circ}$ & $\stackrel{\mathbb{P}}{\mathrm{P}}$ & . & $\stackrel{\vec{\rho}}{\stackrel{+}{\prime}}$ & $\stackrel{D}{F}$ & - $\stackrel{\Omega}{\tilde{F}}$ & $\stackrel{-1}{\stackrel{\circ}{\circ}}$ \\
\hline E-P & $\Delta$ & 1,9 & $-1,9$ & 156 & 5 & -5 & 168 & 0,6 & $-0,6$ & 90 \\
\hline E-F & $\Delta$ & $-6,7$ & 6,7 & 67 & -6 & 6 & 64 & $-2,6$ & 2,6 & 28 \\
\hline I & $\Delta$ & 4,8 & $-4,8$ & 48 & 1 & -1 & 52 & 1,9 & $-1,9$ & 18 \\
\hline \multirow[t]{3}{*}{ Total } & & 35 & 236 & 271 & 71 & 213 & 284 & 61 & 75 & 136 \\
\hline & & $\mathrm{X}^{2}$ & $\mathrm{df}$ & $p$ & $\mathrm{X}^{2}$ & $\mathrm{df}$ & $p$ & $\mathrm{X}^{2}$ & $\mathrm{df}$ & $p$ \\
\hline & & $\overline{10,3}$ & 2 & ,006 & 3,9 & 2 & 143 & 1,8 & 2 & 407 \\
\hline
\end{tabular}

Grouping the sample according to people's education level doesn't seem to influence difference in attributing impoverishment among Catholics and atheists.

TABLE XI: EDUCATION LEVEL AS IV - PRACTICING RESPONDENTS

\begin{tabular}{|c|c|c|c|c|c|c|c|c|c|}
\hline Education & & Low & & & Mediu & & & Higl & \\
\hline Attrib. & $\stackrel{\rightleftarrows}{F}$ & $\stackrel{?}{\rightleftarrows}$ & $\stackrel{-}{\circ}$ & $\stackrel{p}{F}$ & $\stackrel{?}{\rightleftarrows}$ & $\stackrel{-1}{\stackrel{\leftrightarrow}{+}}$ & $\stackrel{P}{F}$ & $\stackrel{\overbrace{}}{\rightleftarrows}$ & $\stackrel{-}{\circ}$ \\
\hline E-P & $\Delta \quad 1,9$ & $-1,9$ & 106 & 4,9 & $-4,9$ & 121 & 2,6 & $-2,6$ & 78 \\
\hline E-F & $\Delta-6,1$ & 6,1 & 43 & $-3,9$ & 3,9 & 40 & $-4,8$ & 4,8 & 30 \\
\hline I & $\Delta 4,2$ & $-4,2$ & 36 & -1 & 1 & 43 & 2,1 & $-2,1$ & 16 \\
\hline \multirow[t]{3}{*}{ Total } & 35 & 150 & 185 & 71 & 133 & 204 & 61 & 63 & 124 \\
\hline & $\mathrm{X}^{2}$ & $\mathrm{df}$ & $p$ & $X^{2}$ & $\mathrm{df}$ & $p$ & $\mathrm{X}^{2}$ & $\mathrm{df}$ & $p$ \\
\hline & 9,12 & 2 &, 010 & 2,66 & 2 & ,264 & 4,51 & 2 &, 105 \\
\hline
\end{tabular}

Practice seems to have a different - scarce - influence on attributional style than faith, although their - obvious relation: dividing sample according to sex, trends remain alike (and significant) for men. In the case of women, trends change for internal attributions: atheists get less internalist whereas Catholics get more internalist than expected.

As seen in case of faith, educational level seems not to influence relation among practicing Catholics and atheists about their attributive style. Significance drops a little, but for one crossing, but trends remain almost the same as considering the entire sample.

\section{CONCLUSION}

This research has been carried out with the aim of getting to the core of the matter about attitudes towards the causes of poverty, a multidimensional topic influenced by a wide range of socio-economic factors: political orientation, educational level, age, income, sex, but also religious beliefs. Religion, indeed, has a strong impact on ways people see and consider reality around them [19], [21], [29], [30], [33]. Analyses we have conducted have confirmed that, in the matter of causal attribution for poverty, this impact exists. Next step has been to observe relation between religion and attributional beliefs "net of" other socio-economic characteristics: educational level, income, sex.

Education has a strong power in shaping attitudes towards impoverishment: being more awakened of a particular complex situation, often related to a higher educational level (or to the experience related to age. [17]), can promote a different idea of the phenomenon; i.e. the assumption of a vision taking into account a wider range of factors.

If we examine literature, some studies show opposing outcomes: Kreidl [6] finds a negative correlation between education levels and fatalistic explanations: the more education increases, the more fatalistic explanations decrease. Lever [34], notes that people with a high-level education (graduated and post-graduated people) has attitudes towards Poverty as a problem arising from inside an individual. Slagsvold and Sorensen [35] argue that a higher level of education is interconnected with a higher sense of control over events. The most part of literature, on the other hand, shows how people with a lower level of education tend to explain poverty as a problem arising from inside the individual more than people with a higher one do.

The correlation between economic status and attributions is easy to understand according to the concept of 'defensive externality': the tendency demonstrates that people having a not good economic status choose external explanations of poverty. On the contrary, people who have a good economic status attribute their good/bad social status to individual, not to context or fatalistic factors. This outcome seems also to recall the Learned Helplessness Theory (it examines the effects of exposing individuals to aversive events which they cannot control: this produces the motivational, cognitive, and emotional effects of uncontrollability. [36]): those who belong to a low income bracket, facing the perception of "failure", tend to attribute events to factors beyond their means.

Concluding this overview about relation between socioeconomic factors and attitude towards impoverishment, sex has emerged as another strong intervening variable: many studies highlight that women are often more externalist than men whereas men are more internalist than women [17], [18], [37], [38]. It suggests cultural explanations: the male figure of "bread-winner", responsible for socioeconomic condition of his family and woman, influences by a past in which faced problems beyond her personal control.

Analyses have showed that in specific context in which this study has been carried out, Italy, relation between religious faith/non faith and beliefs about impoverishing reasons basically seems to hold up, in spite of other socioeconomic characteristics. Some of them seem to 
"modulate" that relation (mainly sex), proving their strong relation with people's attitudes and reaffirming the importance of taking into account complexity of relations into social sciences [39]. Finally, these outcomes fosters the growth of knowledge about link between presence/absence of religious beliefs and personal approach to social phenomena in a context in which religion is so much important in most people's life.

Furthermore, the importance of studies like those we have just talked about is underlined by Schiller: "Which view of poverty we ultimately embrace will have a direct bearing on the public policies we pursue." [19]. Interventions for contrasting poverty are highly influenced by the individual vision of such a phenomenon: in a few words, a policymaker who thinks that causes of poverty have to be detected in the individual's characteristics or lacks, will intervene on this by making policies that facilitate a person to improve his background. On the contrary, an intervention for promoting job-providing (as Rank suggests) reflects the attribution for poverty to factors external to the individual and to context inefficiency. Furthermore, interventions perceived as but as a result of debate and sharing, are surely much more effective because they are part and parcel of a participative process whose aim is to promote involvement and empowerment.

\section{REFERENCES}

[1] J. B. Rotter, "Generalized expectancies for internal versus external control of reinforcement," Psych Monog, vol. 80, 1996.

[2] A. Furnham, "Poverty and wealth," in S. C. Carr et al. (eds.), Poverty and Psychology: From Global Perspective to Local Practice, New York: Kluwer Academic Plenum, 2003.

[3] J. R. Kluegel and E. R. Smith, "Beliefs about stratification," Ann. Rev of Soc, vol. 7, pp. 29-56, 1981.

[4] T. K. Bradshaw, "Theories of poverty and anti-poverty programs," $J$. of the Comm. Dev. Soc., vol. 38, no. 1, pp. 7-25, 2007.

[5] R. Blank, "Selecting among anti-poverty policies: can an economist be both critical and caring," Rev. of soc. Econ, vol. 61, no. 4, pp. 447469, 2003.

[6] M. Kreidl, "Perception of poverty and wealth in post-communist and western countries," Soc. Just. res., vol. 13, no. 2, pp. 151-175, 2000.

[7] G. Wilson, "Toward a revised framework for examining beliefs about the causes of poverty," The Soc. Quart., vol. 37, no. 3, pp. 413-428, 1996.

[8] E. R. Smith and J. R. Kluegel, Causal Attribution Outside the Laboratory: Explaining Poverty, Am. Soc. Ass, 1981.

[9] J. Feagin, Subordinating the Poor, Englewood Cliffs, Prentice-Hall, 1975.

[10] N. Abercrombie and B. S. Turner, "The Dominant Ideology Thesis," The Brit. J. of Soc., vol. 29, no. 2, pp. 149-170, 1978.

[11] S. Hilgartner and C. L. Bosk, "Rise and fall of social problems: A Public Arenas Model," The Am. J. of Soc., vol. 94, no. 1, pp. 53-78, 1988.

[12] J. Gwartney and T. McCaleb, "Have antipoverty programs increased poverty?" Cato J., vol. 5, no. 1, pp. 1-16, 1985.

[13] R. Moffitt, "Incentive effects of the U.S. welfare system. A review," Journal of Economic Literature, vol. 30, no. 1, pp. 1-61, 1992.

[14] D. Hine and C. Montiel, "Poverty in developing nations: a crosscultural analysis," Eur. J. of Soc. Psych., vol. 29, pp. 943-959, 1999.

[15] R. Nasser, S. Singhal, and K. Abouchedid, "Causal Attributions for Poverty among Indian Youth," Curr. Res. in Soc. Psych., vol. 11, no. 1 , pp. 1-13, 2005.

[16] J. P. Sher, "School based community development corporations: A new strategy for education and development in rural America," in J. P. Sher (ed.), Education in Rural America, Boulder, Westview, pp. 291346, 1977.

[17] M. Norcia and A. Rissotto, "Social perception and attribution of causality for poverty: which is the influence of thinking to myself or to others?" in Proc. 2nd ICASS, USA: Newark, vol. 2, pp. 420-427, 2012.
[18] M. Norcia, A. Castellani, and A. Rissotto, "The process of causal attribution of poverty: preliminary results of a survey in Italy," Int. J. of Sustain. Dev., vol. 1, no. 2, pp. 85-97, 2010.

[19] M. Hunt, "Religion, Race/Ethnicity, and Beliefs about Poverty," Soc Sci. Quart., vol. 83, no. 3, 2002.

[20] C. Kempf. (1912). "Theodicy." in the Catholic Encyclopedia. New York: Robert Appleton Company. Retrieved January 25. 2013 [Online]. Available: http://www.newadvent.org/cathen/14569a.htm.

[21] J. Feagin, "Poverty: we still believe that God helps those who help themselves," Psych. Today, vol. 1, pp. 101-129, 1972

[22] J. R. Kluegel and E. R. Smith, Beliefs about inequality: Americans views of what is and what ought to be, Aldine de Gruyter, New York, 1986.

[23] J. R. Kluegel and E. R. Smith, "Cognitive and social bases of emotional experience: Outcome, attribution, and affect," J. of Pers. and Soc. Psych., vol. 43, no. 6, pp. 1129-1141, 1982.

[24] Rapporto Italia 2006, Roma: Eurispes, 2006.

[25] F. Garelli, Religione allitaliana. L'anima del Paese messa a nudo. Bologna: Il Mulino, 2011.

[26] H. Levenson, "Differentiating among internality, powerful others, and chance," in H. M. Lefcourt (ed.), Research with the locus of control construct: Assessment methods, New York: Academic Press, vol. 1, pp. 15-63, 1981.

[27] European Value Study, Tilburg: Tilburg University, 2008.

[28] R. Robinson and W. Bell, "Equality, Success, and Social Justice in England and the U.S.," Am. Soc. Rev., vol. 43, no. 2, pp. 125-143, 1978.

[29] M. Hovemyr, "The Attribution of Success and Failure as Related to Different Patterns of Religious Orientation," Int. J. for the Psych. of Religion, vol. 8, no. 2, pp. 107-124, 1988.

[30] R. Nasser and K. Abouchedid, "Causal attribution of poverty among Lebanese students," Curr. Res. in Soc. Psych., vol. 6, no. 14, 2001.

[31] R. Nisbett, The Geography of Thought: How Asians and Westerners Think Differently And Why, New York: The Free Press, 2003.

[32] Eurostat, Income Poverty and Material Deprivation in European Countries, Luxembourg: Publications Office of the European Union, 2010.

[33] O. D. Gumus, "Differences in System Justification with respect to Gender, Political Conservatism, Socio-Economic Status and Religious Fundamentalism," Procedia - Soc. and Behav. Sci., vol. 30, pp. 2607-2611, 2011.

[34] J. P. Lever and L. V. Trejo, "Pobreza y Locus of control," Interam. J. of Psych., vol. 38, no. 2, pp. 225-240, 2004

[35] B. Slagsvolds and A. Sørensen, "Age, education, and the gender gap in the sense of control," The Int. J. of Ag. and Hum. Dev., vol. 67, no. 1, pp. 25-42, 2008

[36] L. Abramson and M. Seligman, "Learned Helplessness in Humans: Critique and Reformulation," J. of Ab. Psych., vol. 87, no. 1, pp. 4974, 1978.

[37] M. F. Fox and V. Ferri, "Women, men, and their attributions for success in academe," Soc. Psych. Quart., vol. 55, no. 3, pp. 257-271, 1992.

[38] C. Cozzarelli, A. V. Wilkinson, and M. J. Tagler, "Attitudes toward the Poor and Attributions for Poverty," J. of Soc. Issues, vol. 57, pp. 207-227, 2001.

[39] P. Corbetta, La ricerca sociale: Metodologia e tecniche, Bologna: Il Mulino, 2003.

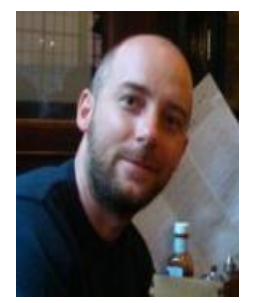

Maurizio Norcia was born in Rome in 1977, February the 10th. He graduated in Social Psychology at University of Rome "Sapienza" and, later, earned a 2nd level Master degree in Research Methodology. Norcia is currently a young researcher at Italian National Research Council. His main research topics is about quality of life and wellbeing and, as a consequence, poverty and deprivation and in building a multidimensional model of poverty as a global loss of wellbeing, considering not only traditional aspects - as low income - but trying to study other fundamental aspects like aims, valued functionings and capabilities (from the Senian point of view) and other psychological aspects related to perceptions, representations and causal attributions. Recent publications: Norcia, M., Rissotto, A. (2012) "Social perception and attribution of causality for poverty: which is the influence of thinking to me or to others?" 2nd ICASS. Vol.2, pp.420-427. IERI, USA: Newark. Norcia, M., Rissotto, A. (2012). "Words on Poverty: Preliminary Research Results in Italy". International Journal of Sustainable Development, Vol. 4, No. 8, pp. 47-54 Norcia, M., Rissotto, A., Noci, E. (2012) "Adopting refined functionings in studying poverty: a pilot study in Italy," 2nd ICASS. Vol.2, pp.411-419. IERI, USA: Newark. 